\title{
VERTICAL MULCHING E MANEJO DA ÁGUA EM SEMEADURA DIRETA ${ }^{(1)}$
}

\author{
Sandra Maria Garcia ${ }^{(2)}$ \& Afranio Almir Righes ${ }^{(3)}$
}

\begin{abstract}
RESUMO
A intensa mobilização do solo no sistema cultivo convencional causou degradação da estrutura, compactação e adensamento do solo abaixo da camada arável, reduzindo a macroporosidade e a taxa de infiltração de água no solo, com conseqüente aumento de escoamento superficial, de erosão e de assoreamento de rios e de reservatórios. A semeadura direta, que protege a superfície do solo, praticamente controlou a perda por erosão hídrica, os terraços foram eliminados, pelos agricultores, e a conseqüência foi maior escoamento superficial do que no sistema cultivo convencional. Com o objetivo de avaliar o comportamento hidrológico do vertical mulching em semeadura direta, em relação ao escoamento superficial, realizou-se esta pesquisa nos anos agrícolas 2002/2003 e 2003/2004, em Latossolo Vermelho distrófico típico, na região fisiográfica do planalto médio do Rio Grande do Sul, isto é, um experimento em escala de campo, com parcelas sem vertical mulching, com vertical mulching a cada $10 \mathrm{~m}$ e com vertical mulching a cada $5 \mathrm{~m}$, no delineamento de blocos ao acaso com três repetições. Sulcos em nível, perpendiculares ao declive, com dimensões de $0,08 \mathrm{~m}$ de largura por $\mathrm{x}$ 0,38 $\mathrm{m}$ de profundidade, foram abertos e preenchidos com palha compactada o suficiente para prevenir desmoronamento das paredes do sulco. No ciclo da cultura da soja e do trigo foram simuladas chuvas com duas intensidades, 70 e $106 \mathrm{~mm} \mathrm{~h}^{-1}$. Foram determinados o escoamento superficial, a taxa de infiltração básica de água no solo e a concentração de nutrientes e de CO no escoamento superficial. Os resultados indicam que o vertical mulching na semeadura direta reduz, significativamente, o volume do escoamento superficial aumenta a taxa de infiltração básica de água no solo e reduz também as perdas totais de nutrientes e de CO devido ao menor volume de água no escoamento superficial.
\end{abstract}

Termos de indexação: enxurrada, infiltração de água, erosão, deflúvio, perdas de nutrientes.

(1) Parte da Tese de Doutorado do primeiro autor apresentada ao Programa de Pós-graduação em Engenharia Agrícola da Universidade Federal de Santa Maria - UFMS. Financiado com recursos do CT-Hidro/CNPq. Recebido para publicação em junho de 2006 e aprovado em novembro de 2007.

(2) Engenheira Florestal, Universidade Federal de Santa Maria - UFSM. Campus Universitário, CEP 97105-900 Santa Maria (RS). Bolsista do CNPq. E-mail: sandramgarciars@yahoo.com.br

(3) Professor do Curso de Engenharia Ambiental, Centro Universitário Franciscano - UNIFRA. Rua dos Andradas 1614, CEP 97010032 Santa Maria (RS). E-mail: righes@unifra.br 


\title{
SUMMARY: VERTICAL MULCHING AND WATER MANAGEMENT IN NO TILLAGE SYSTEM
}

\begin{abstract}
Intensive soil mobilization in the conventional tillage system has caused soil structure degradation, soil compaction below the arable layer, and decreased macroporosity. These changes resulted in reduced soil water infiltration rate and increased runoff, soil erosion and sedimentation in rivers and reservoirs. In the no tillage system the water erosion from the soil surface is practically controlled, and the terraces were eliminated by the farmers. Nevertheless, the surface flow is higher than it was in the conventional tillage system. With the objective of evaluating the hydrological behavior of vertical mulching in no tillage systems as related to runoff, this study was developed in the growing seasons of 2002/2003 and 2003/2004 on a Red Latosol (Oxisol) in the Planalto Médio region of Rio Grande do Sul State, Brazil. A field experiment was installed using plots without vertical mulching, with vertical mulching at every $10 \mathrm{~m}$ and with vertical mulching at every $5 \mathrm{~m}$. It was used a randomized block design with three replications. Leveled furrows of vertical mulching, perpendicular to the soil slope (0.08 m wide by $0.38 \mathrm{~m}$ deep) were dug and filled with straw compacted enough to stabilize the furrow sides. Rainfall intensities of 70 and $106 \mathrm{~mm} \mathrm{~h}^{-1}$ were simulated on soybean and wheat to determine runoff, soil water infiltration rate, and nutrient and organic carbon concentration in the runoff. The results showed that vertical mulching in no tillage significantly reduces surface runoff and increases the water infiltration rate into the soil. It also reduces the total nutrient and organic carbon losses due to the reduction of water runoff.
\end{abstract}

Index terms: runoff, water infiltration, erosion, surface flow, nutrient losses.

\section{INTRODUÇÃO}

A ação do homem no ambiente quase sempre foi fundamentada em um interesse primordial: a procura do bem-estar, sendo seu primeiro objetivo a obtenção de alimentos. Por esse caminho, poluiu e modificou o ambiente com conseqüências muitas vezes desastrosas. O aperfeiçoamento do conhecimento técnico-científico contribuiu para o melhor entendimento da natureza, mas a degradação do solo já havia ocorrido.

No Rio Grande do Sul, a expansão da agricultura e da pecuária deu-se, em parte, às custas da destruição das florestas nativas, modificando, drasticamente, a paisagem da região, principalmente durante o período da colonização.

A intensa mobilização do solo para o cultivo de trigo e de soja, associada à provável translocação de argila natural da camada arável para a camada subsuperficial, provocou compactação e adensamento com aumento da densidade, degradação da estrutura e redução da macroporosidade do solo. Como conseqüência, ocorreram redução na taxa de infiltração de água no solo, erosão hídrica e assoreamento de rios e de reservatórios. Nessa região, a taxa básica de infiltração de água no solo era de $180 \mathrm{~mm} \mathrm{~h}^{-1}$, em floresta nativa, e passou para $8 \mathrm{~mm} \mathrm{~h}^{-1}$, em solos cultivados durante 50 anos, com as culturas trigo e soja em sucessão no sistema de preparo convencional (Righes et al., 2002). Visando minimizar esse problema, surgiu o terraceamento. Contudo, essa técnica apenas administrava a água das enxurradas, enquanto a baixa taxa de infiltração ainda persistia.

Finalmente, na década de 1980, a semeadura direta difundiu-se, reduzindo consideravelmente as perdas de solo por erosão, o que motivou os agricultores a retirarem, indiscriminadamente, os terraços, justificados pela redução de perdas de solo por erosão e pelo aumento da capacidade operativa das máquinas agrícolas. Porém, considerando longas pendentes, a retirada dos terraços aumenta o fluxo de água na superfície do solo. A semeadura direta, com méritos, foi difundida entre os agricultores em todo o País. Todavia, o tráfego de máquinas pesadas contribuiu para o aumento da compactação do solo, reduzindo ainda mais a taxa de infiltração de água no solo e causando perdas de água, de nutrientes e de matéria orgânica no escoamento superficial.

Considerando a necessidade de consolidação da semeadura direta nos solos profundos típicos do planalto médio do Rio Grande do Sul e a demanda por técnicas que permitam a sustentabilidade da exploração agrícola, conservando o ambiente a médio e longo prazos, este trabalho teve como objetivos: (a) determinar o efeito do vertical mulching no escoamento superficial da água em semeadura direta com chuva simulada; (b) avaliar o efeito do vertical mulching sobre a taxa de infiltração de água no solo em semeadura direta com chuva simulada; e (c) determinar a concentração de nutrientes e de CO na água do 
escoamento superficial, em função do vertical mulching em semeadura direta.

\section{MATERIAL E MÉTODOS}

A pesquisa (projeto integrado Universidade Federal de Santa Maria - UFSM, Centro Nacional de Pesquisas de Trigo - Embrapa Trigo e Semeato S.A. Indústria e Comércio) foi realizada na Área II da Embrapa Trigo, Passo Fundo - RS, situada na latitude de $28^{\circ} 15^{\prime} 41^{\prime \prime}$ S e longitude de $52^{\circ} 24^{\prime} 45^{\prime} \mathrm{O}$, com altitude aproximada de $709 \mathrm{~m}$, na região fisiográfica do planalto médio do Rio Grande do Sul. A precipitação pluvial média anual é de $1.664 \mathrm{~mm}$ com temperaturas médias: máxima média: $23,3{ }^{\circ} \mathrm{C}$; mínima média: $12,9^{\circ} \mathrm{C}$; e média anual: $17,5^{\circ} \mathrm{C}$. A vegetação predominante é de matas nativas em campos abertos (IPAGRO, 1989).

O solo da área experimental pertence à Unidade de Mapeamento Passo Fundo, classificado como Latossolo Vermelho distrófico típico textura muito argilosa, com argila em torno de $600 \mathrm{~g} \mathrm{~kg}^{-1}$, relevo ondulado com substrato basalto fase floresta subtropical subperenifólia com araucárias (Embrapa, 1999).

O experimento consistiu de três tratamentos e três repetições em delineamento experimental de blocos ao acaso, totalizando nove parcelas experimentais: (tratamento 1- testemunha) semeadura direta sem vertical mulching; (tratamento 2-T5) semeadura direta com vertical mulching a cada $5 \mathrm{~m}$; (tratamento 3-T10) semeadura direta com vertical mulching a cada $10 \mathrm{~m}$.

\section{Instalação do experimento}

A implantação dos tratamentos ocorreu no ano agrícola 2002/2003 em área cultivada com soja, cultivar BR 317, em semeadura direta. Após a colheita da soja, foi semeado trigo, cultivar BRS 179. As culturas foram semeadas no sentido longitudinal das parcelas com dimensões de 3,5 x 22,5 m (Figura 1). A área total de cada parcela foi de 78,75 m² (Mondardo et al., 1978). A declividade média do terreno era de $0,075 \mathrm{~m} \mathrm{~m}^{-1}$. A delimitação lateral das parcelas foi realizada com chapas de aço galvanizada com $0,15 \mathrm{~m}$ de largura, introduzidas no solo até a profundidade de $0,10 \mathrm{~m}$.

Para evitar que a água infiltrada em um sulco de vertical mulching de uma parcela fosse deslocada para o sulco de outra parcela, foram introduzidas, na divisão das parcelas, chapas de aço galvanizado com dimensões de $0,50 \times 0,25 \mathrm{~m}$. Na parte inferior das parcelas, foram instaladas calhas metálicas coletoras de enxurrada, que direcionavam o fluxo para as calhas medidoras.

Os tratamentos foram instalados no dia 9 de janeiro de 2003, na fase inicial do ciclo da soja. Os sulcos de

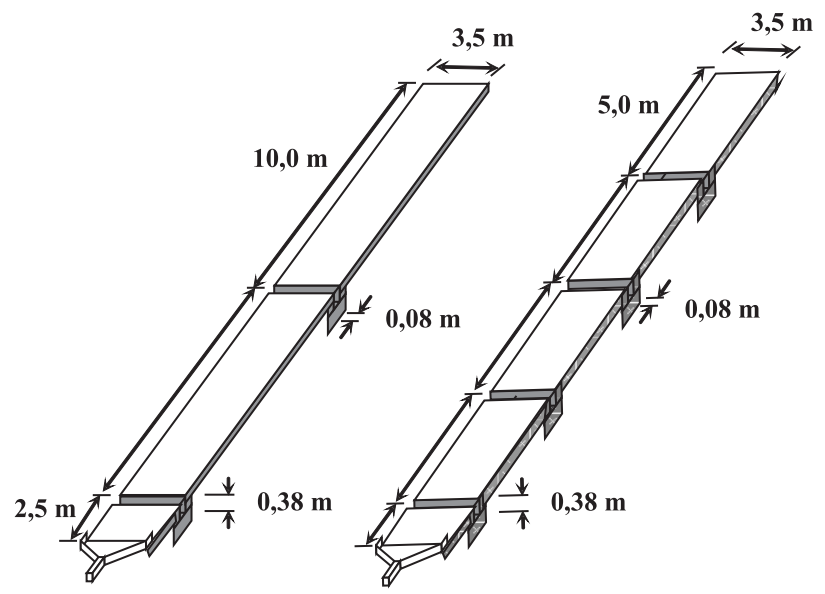

Figura 1. Esquema das parcelas experimentais e dos tratamentos com sulcos de vertical mulching a cada $10 \mathrm{~m}$ e a cada $5 \mathrm{~m}$

vertical mulching foram abertos, em nível, perpendicularmente ao declive, com dimensões de 3,5 m de comprimento $\mathrm{x} 0,08 \mathrm{~m}$ de largura e 0,38 m de profundidade, utilizando-se uma valetadeira rotativa, da Semeato S.A. Indústria e Comércio, usada para drenagem localizada em solos de várzeas. O solo proveniente da abertura dos sulcos foi uniformemente distribuído na superfície do terreno. Os sulcos foram manualmente preenchidos com palha de trigo, compactada o suficiente para dar estabilidade às paredes do sulco, evitando-se o colapso em períodos de chuva.

\section{Determinação da cobertura do solo e da quantidade de matéria seca}

Para a determinação da cobertura do solo, seguiuse o método do quadrado entrelaçado com $0,5 \mathrm{~m}$ de lado, apresentado por Veiga \& Wildner (1993). A determinação da massa de matéria seca sobre o solo foi realizada em quatro repetições, em um quadrado de $0,5 \mathrm{~m}$ de lado $\left(0,25 \mathrm{~m}^{2}\right)$ lançado aleatoriamente sobre o solo. Todos os resíduos de plantas dentro deste quadrado foram coletadas e secas em estufa a $65^{\circ} \mathrm{C}$. Determinou-se a massa de matéria seca por unidade de área.

\section{Simulação da chuva}

Para aplicar as chuvas simultaneamente sobre três parcelas (um bloco), foi utilizado um simulador de chuva com aspersores fixos, usados em pivô central, montados com sobreposição da área de molhamento para atingir a intensidade desejada. Antes da simulação da chuva foi determinado o coeficiente de uniformidade de Christiansen, segundo Benami \& Ofen (1984). Para as diferentes intensidades de chuva simuladas, o coeficiente variou de 70 a $80 \%$. O simulador continha uma linha principal com tubulação de $85 \mathrm{~mm}$ de diâmetro, quatro linhas laterais de $21 \mathrm{~m}$ de comprimento, com $60 \mathrm{~mm}$ de 
diâmetro, e sete aspersores espaçados de 3,5 m eqüidistantes ao longo da linha. A fonte de água foi um açude distante $200 \mathrm{~m}$ da área experimental. Para pressurizar a água, utilizou-se um conjunto motobomba, marca KSB. Para regular a rotação do motor elétrico, usou-se um conversor de freqüência, marca WEG, possibilitando o ajuste exato da pressão de serviço, em $200 \mathrm{kPa}$. Para avaliar o efeito do vertical mulching, aplicaram-se duas intensidades de precipitação: 70 e $106 \mathrm{~mm} \mathrm{~h}^{-1}$.

As simulações das chuvas foram realizadas no ciclo da cultura da soja e do trigo. Na cultura da soja, foram realizadas nos dias 30 e 31 de maio, aproximadamente 25 dias após a colheita da cultura da soja. No ciclo do trigo, nos dias 18 e 19 de agosto, aproximadamente 60 dias após a semeadura.

Com o simulador instalado sobre a área de um bloco, simulou-se chuva com intensidade de precipitação de $70 \mathrm{~mm} \mathrm{~h}^{-1}$ até obter taxa de enxurrada constante nas calhas medidoras. Após esta simulação, substituíramse os bocais de 4,0 $\mathrm{mm}$ de diâmetro pelos de $4,4 \mathrm{~mm}$ em todos os aspersores, simulando-se a chuva de intensidade de $106 \mathrm{~mm} \mathrm{~h}^{-1}$ até obter a taxa constante de escoamento superficial (Figura 2).

Antes da simulação de cada intensidade de chuva, coletaram-se amostras de solo na parte mediana das camadas de $0-0,15 ; 0,15-0,30$; e $0,30-0,40 \mathrm{~m}$ de profundidade para a determinação do conteúdo de água no solo realizada pelo método gravimétrico.

\section{Escoamento superficial}

$\mathrm{O}$ volume de água escoado de cada parcela foi captado e conduzido às calhas medidoras tipo HS (0,18 $\mathrm{m}$ de profundidade), com poço tranqüilizador (Brakensiek et al., 1979). Nesses poços, foram instalados sensores de nível, alimentado por uma bateria de $12 \mathrm{~V}$, para o monitoramento da altura da lâmina de água escoada na calha medidora com leitura a cada trinta segundos (Figura $2 b$ ). Os sensores emitiam sinal em $\mathrm{mV}$ a um data logger, que armazenava os dados em bits.

Para obter o volume de água escoada nas calhas medidoras, realizou-se a calibração dos sensores para transformar os dados armazenados em bits para unidades de vazão de escoamento, $\mathrm{L} \mathrm{min}^{-1}$. A calibração dos sensores foi realizada posicionando as calhas medidoras em seqüência, aproveitando o desnível do terreno, fazendo com que vazões conhecidas por meio de hidrômetros de precisão aplicadas na primeira calha passassem pelas calhas seguintes.

Considerando que o transporte de partículas de solo no escoamento superficial era insignificante, esta propriedade não foi avaliada. Após a coleta de vários dados, relacionou-se a vazão conhecida com os dados de leitura, obtendo-se, por regressão, a equação de calibração para cada sensor.

$$
\begin{gathered}
\text { Sensor 1: } Q=9,53828-0,50767 \text { bits }+ \\
0,0086569 \text { bits }^{2} \\
\mathrm{R}^{2}=0,972
\end{gathered}
$$

$$
\begin{gathered}
\text { Sensor } 2: Q=1,64932-0,40673 \text { bits }+ \\
0,0067458 \text { bits }^{2} \\
\mathrm{R}^{2}=0,971
\end{gathered}
$$

$$
\begin{gathered}
\text { Sensor 3: } Q=41,54574-1,19654 \text { bits }+ \\
0,00917397 \text { bits }^{2} \\
\mathrm{R}^{2}=0,973
\end{gathered}
$$

sendo $Q=$ vazão das calhas medidoras $\left(\mathrm{L} \mathrm{min}^{-1}\right)$; e bits $=$ unidade de armazenamento no data logger dos dados lidos pelos sensores de nível.
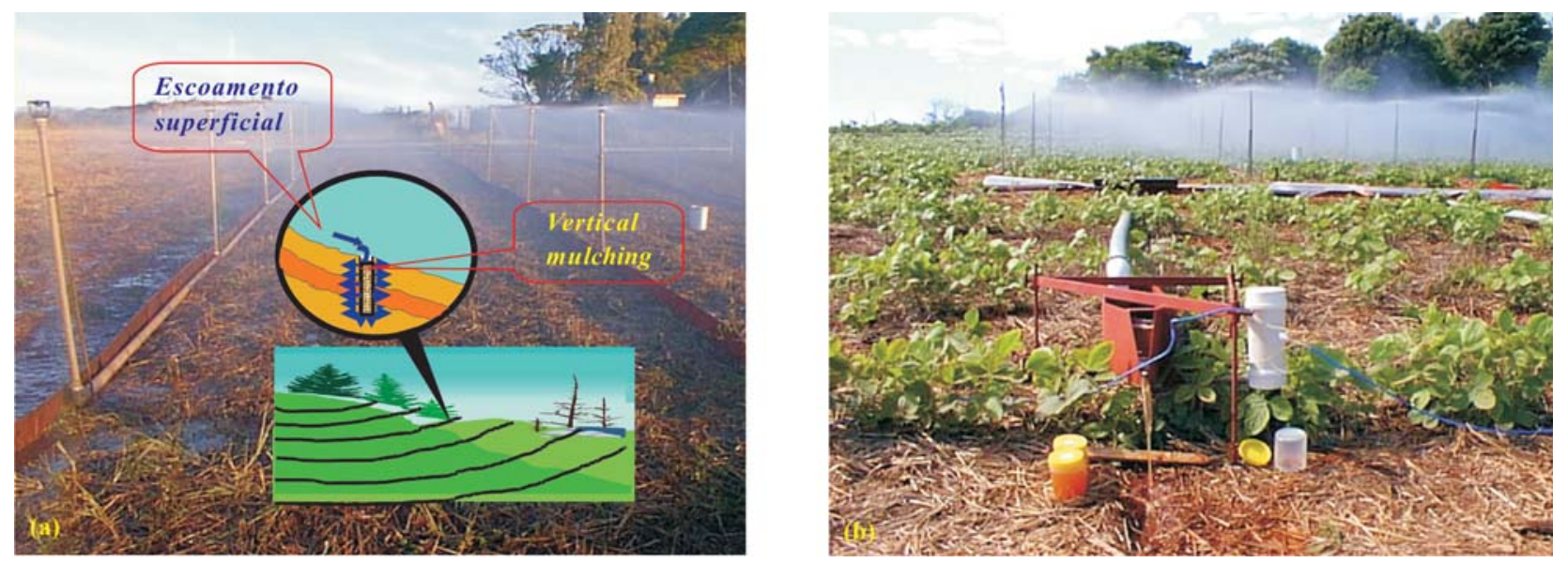

Figura 2. Simulação de chuva em um dos blocos e (a) detalhe da localização do vertical mulching em uma lavoura; (b) vista da parcela com a simulação de chuva e determinação do escoamento superficial por meio da calha-HS. 
Após as simulações da chuva, os dados armazenados no data logger foram transferidos para um computador portátil. Utilizando as equações de calibração dos sensores 1,2 e 3, obteve-se a vazão de escoamento superficial em cada parcela experimental. Os valores em L min ${ }^{-1}$ foram transformados em $\mathrm{mm} \mathrm{h}^{-1}$.

Com os dados de escoamento superficial aplicados à Equação 4, determinou-se o coeficiente de escoamento superficial para cada intensidade de chuva, na semeadura direta sem vertical mulching e com vertical mulching a cada 5 e $10 \mathrm{~m}$ de espaçamento:

$$
C=\frac{E S}{P t}
$$

sendo $C=$ coeficiente de escoamento; $E S=$ volume de escoamento superficial $\left(\mathrm{m}^{3}\right)$; e $\mathrm{Pt}=$ volume total precipitado $\left(\mathrm{m}^{3}\right)$.

\section{Taxa de infiltração básica de água no solo}

A taxa de infiltração básica de água no solo (Tib) foi determinada pela diferença entre a intensidade de precipitação hídrica aplicada e a taxa constante de escoamento de cada parcela (Equação 5):

$$
T i b=P-E S c
$$

sendo Tib = taxa de infiltração básica de água no solo $\left(\mathrm{mm} \mathrm{h}^{-1}\right) ; P=$ precipitação hídrica aplicada $\left(\mathrm{mm} \mathrm{h}^{-1}\right)$; e $E s c=$ taxa de escoamento superficial $\left(\mathrm{mm} \mathrm{h}^{-1}\right)$.

\section{Nutrientes e carbono orgânico no escoamento superficial}

A determinação de concentração de nutrientes e de $\mathrm{CO}$ no escoamento superficial seguiu o método proposto por Tedesco et al. (1995). A adubação aplicada no experimento foi de $250 \mathrm{~kg} \mathrm{ha}^{-1}$ de NPK na formulação 5-20-20.

A coleta de escoamento superficial para análises químicas foi realizada nas simulações de chuva aplicadas no ciclo da cultura da soja e do trigo. De cada parcela, foram coletadas amostras de aproximadamente $0,5 \mathrm{~L}$ a cada 5 min desde o início até o fim do escoamento superficial, e colocadas em recipiente maior. Em seguida, foram homogeneizadas e acondicionadas em frascos de polietileno e congeladas até a realização das análises de acordo com método descrito pela CETESB (1989). Foram realizadas determinações dos teores de $\mathrm{P}, \mathrm{K}, \mathrm{N}$ total e $\mathrm{CO}$.

Obtidos os teores de nutrientes e de $\mathrm{CO}$, calcularam-se as quantidades perdidas por parcela $\mathrm{e}$ por intensidade de chuva, considerando os valores totais de escoamento superficial acumulado. Em seguida, esses valores foram comparados utilizando-se o programa estatístico SAS. O teste de médias empregado foi o de Duncan, a $5 \%$. As médias foram comparadas entre tratamentos e dentro do ciclo da cultura de soja e de trigo.

\section{RESULTADOS E DISCUSSÃO}

\section{Conteúdo de água no solo antes e após as simulações de chuva}

Os conteúdos volumétricos de água no solo, determinados antes das simulações de chuva, nos três tratamentos, no ciclo da cultura da soja e de trigo, não apresentaram diferença estatística pelo teste de Duncan a $5 \%$. Após as simulações de chuva, os conteúdos volumétricos de água no solo também não apresentaram diferenças estatísticas significativa pelo mesmo teste.

\section{Cobertura do solo e quantidade de palha na superfície}

A massa de matéria seca sobre o solo antes da simulação de chuva, nas duas épocas de avaliação, variou de 2,7 a $3,3 \mathrm{Mg} \mathrm{ha}^{-1}$, não diferindo estatisticamente entre os tratamentos. Desta forma, pode-se afirmar que os tratamentos foram influenciados de maneira semelhante no que diz respeito à percentagem de cobertura do solo sobre o escoamento superficial, resultando nas diferenças atribuídas aos sulcos do vertical mulching. De acordo com Heckler \& Salton (2002), a percentagem de cobertura do solo com palha é um dos principais fatores que interferem na infiltração de água no solo. A constante cobertura da superfície do solo diminui as perdas de água por escoamento superficial.

\section{Escoamento superficial}

Avaliando o efeito do espaçamento entre sulcos do vertical mulching, constata-se que não houve diferença significativa entre os tratamentos na primeira época (Quadro 1). Provavelmente, com a intensidade de chuva de $70 \mathrm{~mm} \mathrm{~h}^{-1}$, o escoamento superficial foi totalmente absorvido por ambos os tratamentos.

Conforme Pruski (2001), o escoamento superficial ocorre a partir do momento em que a intensidade da precipitação pluvial excede a taxa de infiltração de água no solo, a qual tende a decrescer com o tempo devido ao umedecimento do solo. Em termos percentuais do volume total precipitado, o tratamento sem vertical mulching perdeu $14,7 \%$; com vertical mulching a cada $10 \mathrm{~m}, 4,7 \%$; e com vertical mulching a cada $5 \mathrm{~m}, 3,0 \%$. Esses valores correspondem a 12,86, 4,11 e 2,62 $\mathrm{mm}$ respectivamente, que foram perdidos do volume total precipitado pluvial $(87,5 \mathrm{~mm}) \mathrm{em}$ 75 min de simulação.

Durante o ciclo da cultura do trigo, com chuvas de mesma intensidade e duração, não ocorreu escoamento superficial nos dois tratamentos com vertical mulching. A taxa constante na testemunha foi de $13,4 \mathrm{~mm} \mathrm{~h}^{-1}$, alcançada aos 73,5 min após o início da chuva. O volume total perdido foi de $9,36 \mathrm{~mm}$, que corresponde a $10,7 \%$ do total aplicado. 
Quadro 1. Taxas constantes de escoamento superficial e coeficientes de escoamento em Latossolo Vermelho distrófico típico, obtidos com chuvas simuladas com intensidades de 70 e $106 \mathrm{~mm} \mathrm{~h}^{-1}$ no ciclo da cultura da soja e do trigo, nos tratamentos sem vertical mulching, com vertical mulching a cada 10 m e a cada $5 \mathbf{~ m}$

\begin{tabular}{|c|c|c|c|c|}
\hline \multirow[t]{2}{*}{ Tratamento } & \multicolumn{2}{|c|}{$\begin{array}{c}\text { Taxa constante de escoamento } \\
\text { superficial }\left(\mathrm{mm} \mathrm{h}^{-1}\right)^{(1)}\end{array}$} & \multicolumn{2}{|c|}{$\begin{array}{c}\text { Coeficiente de escoamento } \\
\text { superficial }\end{array}$} \\
\hline & $70 \mathrm{~mm} \mathrm{~h}^{-1}$ & $106 \mathrm{~mm} \mathrm{~h}^{-1}$ & $70 \mathrm{~mm} \mathrm{~h}^{-1}$ & $106 \mathrm{~mm} \mathrm{~h}^{-1}$ \\
\hline & \multicolumn{4}{|c|}{ Ciclo da cultura da soja } \\
\hline Sem vertical mulching & $18,7 \mathrm{a}$ & 39,7 a & 0,147 & 0,275 \\
\hline Vertical mulching a cada $10 \mathrm{~m}$ (T10) & $9,6 \mathrm{~b}$ & $22,9 \mathrm{~b}$ & 0,047 & 0,138 \\
\hline \multirow[t]{2}{*}{ Vertical mulching a cada $5 \mathrm{~m}(\mathrm{~T} 5)$} & $8,5 \mathrm{~b}$ & $22,5 \mathrm{~b}$ & 0,030 & 0,137 \\
\hline & \multicolumn{4}{|c|}{ Ciclo da cultura do trigo } \\
\hline Sem vertical mulching & $13,4 \mathrm{a}$ & 39,5 a & 0,107 & 0,263 \\
\hline Vertical mulching a cada $10 \mathrm{~m}$ (T10) & $0,0 \mathrm{~b}$ & $22,7 \mathrm{~b}$ & 0,000 & 0,126 \\
\hline Vertical mulching a cada $5 \mathrm{~m}$ (T5) & $0,0 \mathrm{~b}$ & $20,2 \mathrm{~b}$ & 0,000 & 0,103 \\
\hline
\end{tabular}

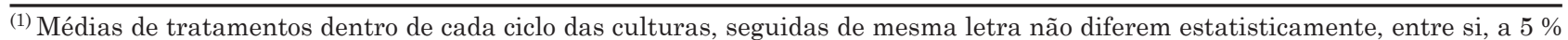
pelo teste de Duncan.

O controle do escoamento superficial do tratamento com vertical mulching a cada $10 \mathrm{~m}$, no ciclo da cultura da soja, em relação à testemunha, foi de 48,66 \%, e a cada $5 \mathrm{~m}$ a redução foi de $54,54 \%$. No ciclo da cultura do trigo, o controle do escoamento superficial foi de $100 \%$ para os tratamentos com vertical mulching. espaçados de 5 e $10 \mathrm{~m}$.

Os menores valores de escoamento superficial nas parcelas com vertical mulching devem-se à eliminação da camada mais compactada, de 0,025 a $0,15 \mathrm{~m}$ de profundidade (Herbes, 2003), pela abertura do sulco. Ultrapassando esta camada de impedimento, o vertical mulching possibilitou o deslocamento da água para ser infiltrada em maior profundidade, aumentando a taxa de infiltração devido à maior percentagem de macroporos nas camadas inferiores, reduzindo consideravelmente o escoamento superficial. O tempo de duração da chuva simulada, com intensidade de $106 \mathrm{~mm} \mathrm{~h}^{-1}$, para o ciclo da soja e do trigo, foi de $32,5 \mathrm{~min}$, totalizando um volume equivalente a uma altura de lâmina de $57,4 \mathrm{~mm}$.

O volume total escoado correspondeu a $27,5 \%$ do total aplicado na testemunha. $\mathrm{O}$ volume total perdido no tratamento com espaçamento entre sulcos de vertical mulching de $10 \mathrm{~m}$ corresponde a $13,8 \%$ $(13,7 \%$ menos que na testemunha). Isso significa que, dos 57,42 $\mathrm{mm}$ aplicados, o tratamento com vertical mulching a cada $10 \mathrm{~m}$ perdeu $7,92 \mathrm{~mm}$ e a testemunha perdeu $15,79 \mathrm{~mm}$. Já o tratamento com vertical mulching a cada $5 \mathrm{~m}$ perdeu $7,86 \mathrm{~mm}$, correspondente a $13,7 \%$ do volume total de água precipitada.

Durante o ciclo do trigo, o volume total de água perdida na testemunha foi de $15,10 \mathrm{~mm}$, correspondente a $26,3 \%$. No tratamento com vertical mulching a cada $10 \mathrm{~m}$, perderam-se $12,6 \%$ do volume total aplicado. Esse valor corresponde a 7,23 mm. O tratamento com vertical mulching a cada $5 \mathrm{~m}$ perdeu $10,3 \%$ do total aplicado, valor que corresponde a $5,91 \mathrm{~mm}$.

A semeadura direta com vertical mulching a cada $10 \mathrm{~m}$ apresentou redução no escoamento superficial de $42,32 \%$ em relação à testemunha, e com vertical mulching a cada $5 \mathrm{~m}$ a redução foi de $43,32 \%$ na primeira época. No ciclo da cultura do trigo, sulcos de vertical mulching a cada $10 \mathrm{~m}$ proporcionaram redução na taxa de escoamento superficial de $42,53 \%$ em relação ao semeadura direta sem vertical mulching, e com vertical mulching a cada $5 \mathrm{~m}$, a redução na taxa de escoamento superficial de água no solo foi de $48,86 \%$.

\section{Infiltração de água no solo}

A taxa de infiltração básica de água no solo na testemunha, sem vertical mulching, apresentou diferença estatística significativa em relação aos tratamentos com vertical mulching, o que não aconteceu entre os tratamentos com diferentes espaçamentos entre sulcos (Quadro 2).

Com chuva simulada de $70 \mathrm{~mm} \mathrm{~h}^{-1}$ no ciclo da cultura da soja, a testemunha, sem vertical mulching, apresentou taxa de infiltração básica de água no solo de $51,3 \mathrm{~mm} \mathrm{~h}^{-1}$. A infiltração acumulada foi $74,6 \mathrm{~mm}$. $\mathrm{O}$ tratamento com vertical mulching a cada $10 \mathrm{~m}$ apresentou taxa de infiltração básica de $60,3 \mathrm{~mm} \mathrm{~h}^{-1}$, e a infiltração acumulada foi de $83,4 \mathrm{~mm}$. Já no tratamento com mulching vertical a cada $5 \mathrm{~m}$, a taxa 
Quadro 2. Taxas de infiltração básicas e infiltrações acumuladas em Latossolo Vermelho distrófico típico, obtidas com chuva simulada com intensidade de 70 e $106 \mathrm{~mm} \mathrm{~h}^{-1}$, no ciclo da cultura da soja e do trigo nos tratamentos sem vertical mulching, com vertical mulching a cada $10 \mathrm{~m}$ e com vertical mulching a cada $5 \mathrm{~m}$

\begin{tabular}{|c|c|c|c|c|}
\hline \multirow[t]{2}{*}{ Tratamento } & \multicolumn{2}{|c|}{ Taxa de infiltração básica } & \multicolumn{2}{|c|}{ Infiltração acumulada } \\
\hline & $70 \mathrm{~mm} \mathrm{~h}^{-1}$ & $106 \mathrm{~mm} \mathrm{~h}^{-1}$ & $70 \mathrm{~mm} \mathrm{~h}^{-1}$ & $106 \mathrm{~mm} \mathrm{~h}^{-1}$ \\
\hline & \multicolumn{2}{|c|}{$\mathrm{mm} \mathrm{h}^{-1(1)}$} & \multicolumn{2}{|c|}{$-\mathrm{mm}$} \\
\hline & \multicolumn{4}{|c|}{ Ciclo da cultura da soja } \\
\hline Sem vertical mulching & $51,3 \mathrm{a}$ & $66,3 \mathrm{a}$ & 74,6 & 41,6 \\
\hline Vertical mulching a cada $10 \mathrm{~m}$ & $60,3 \mathrm{~b}$ & 83,0 a & 83,4 & 49,5 \\
\hline \multirow[t]{2}{*}{ Vertical mulching a cada $5 \mathrm{~m}$} & $61,4 \mathrm{~b}$ & 83,5 a & 84,8 & 49,5 \\
\hline & \multicolumn{4}{|c|}{ Ciclo da cultura do trigo } \\
\hline Sem vertical mulching & 56,5 a & 66,4 a & 78,2 & 42,3 \\
\hline Vertical mulching a cada $10 \mathrm{~m}$ & $\geq 70,0 \mathrm{~b}$ & $83,2 \mathrm{~b}$ & 87,5 & 50,1 \\
\hline Vertical mulching a cada $5 \mathrm{~m}$ & $\geq 70,0 \mathrm{~b}$ & $85,7 \mathrm{~b}$ & 87,5 & 51,5 \\
\hline
\end{tabular}

de infiltração básica atingiu $61,4 \mathrm{~mm} \mathrm{~h}^{-1}$, e a infiltração foi de $84,8 \mathrm{~mm}$ do total de $87,5 \mathrm{~mm}$ precipitados.

Não ocorreu escoamento superficial no ciclo da cultura do trigo, para os tratamentos com mulching vertical a cada 10 e 5 m (Quadro 1), o que significa que a taxa de infiltração básica de água no solo foi igual ou superior a $70 \mathrm{~mm} \mathrm{~h}^{-1}$, e a infiltração acumulada foi $100 \%$, ou seja, 87,5 mm. A taxa de infiltração básica na testemunha foi $56,5 \mathrm{~mm} \mathrm{~h}^{-1}$.

Com a intensidade de chuva simulada de $106 \mathrm{~mm} \mathrm{~h}^{-1}$, os valores da taxa de infiltração básica de água no solo, no ciclo da soja, não diferiram significativamente entre os três tratamentos. Para a testemunha, esse valor foi de $66,3 \mathrm{~mm} \mathrm{~h}^{-1}$ com infiltração acumulada de $41,6 \mathrm{~mm}$. No tratamento com vertical mulching a cada $10 \mathrm{~m}$, a taxa de infiltração básica encontrada foi $83,0 \mathrm{~mm} \mathrm{~h}^{-1}$, e a infiltração acumulada foi 49,5 mm. O valor referente à taxa de infiltração básica de água no solo no tratamento com mulching vertical a cada $5 \mathrm{~m}$ foi de $83,5 \mathrm{~mm} \mathrm{~h}^{-1}$, e o valor da infiltração acumulada foi o mesmo encontrado para o espaçamento de $10 \mathrm{~m}$.

No ciclo da cultura do trigo, com intensidade de chuva simulada de $106 \mathrm{~mm} \mathrm{~h}^{-1}$, a taxa de infiltração básica de água no solo na testemunha, sem vertical mulching, foi de $66,4 \mathrm{~mm} \mathrm{~h}^{-1}$ e totalizou $42,3 \mathrm{~mm}$ de infiltração acumulada, diferindo significativamente dos tratamentos com vertical mulching (Quadro 2). A taxa de infiltração básica de água no solo não diferiu significativamente quando o espaçamento entre os sulcos do vertical mulching passou de $5 \mathrm{~m}$ para $10 \mathrm{~m}$, mantendo, praticamente, os mesmos valores de infiltração acumulada, demonstrando, dessa forma, a importância do vertical mulching no aumento da infiltração de água no solo.

Concluindo, pode-se afirmar que a técnica do vertical mulching em Latossolo Vermelho distrófico, típico, em semeadura direta, aumenta a taxa de infiltração básica de água no solo até $25,30 \%$, se o espaçamento entre sulcos for de $10 \mathrm{~m}$ e até 29,07\% quando o espaçamento entre sulcos é reduzido para $5 \mathrm{~m}$, comparado ao semeadura direta sem vertical mulching.

\section{Concentração de nutrientes e de carbono orgânico no escoamento superficial}

A concentração de nutrientes e a de $\mathrm{CO}$ analisados na água do escoamento superficial não diferem entre si em função dos tratamentos testados (Quadro 3).

Segundo Schick et al. citado por Brignoni et al. (2004), o teor de nutrientes no solo, influenciado pela quantidade de adubos, pela forma de aplicação e pela cobertura e manejo do solo, determina a concentração de nutrientes no escoamento superficial. A maior concentração encontrada em todos os testes foi de CO. Isso se explica pela elevada quantidade dos resíduos vegetais, mantidos na superfície do solo, em semeadura direta (Brignoni et al., 2004).

De acordo com Volk et al. (2004), as maiores concentrações de nutrientes acontecem nos primeiros minutos de enxurrada e diminuem com o tempo. O K apresentou concentrações maiores que as de $\mathrm{P}$ em todos os tratamentos e intensidades de chuva, nas duas épocas (Quadro 3). Resultados semelhantes foram encontrados por Brignoni et al. (2004). 
Quadro 3. Concentrações médias de potássio, fósforo, carbono orgânico, e nitrogênio total no escoamento superficial obtidas com chuva simulada com intensidade de 70 e $106 \mathrm{~mm} \mathrm{~h}^{-1}$, em Latossolo Vermelho distrófico típico, no ciclo da cultura do trigo e da soja em semeadura direta, para os tratamentos sem vertical mulching, com vertical mulching a cada $10 \mathrm{~m}$ e com vertical mulching a cada $5 \mathrm{~m}$

\begin{tabular}{|c|c|c|c|c|}
\hline Tratamento & Potássio & Fósforo & Carbono orgânico & Nitrogênio total \\
\hline & \multicolumn{3}{|c|}{ Concentração em $\left(\mathrm{mg} \mathrm{L}^{-1}\right)^{(1)}$} & - \\
\hline \multicolumn{5}{|c|}{ Intensidade de chuva $106 \mathrm{~mm} \mathrm{~h}^{-1}$ (ciclo da cultura do trigo) } \\
\hline Sem vertical mulching & 3,02 a & $0,32 \mathrm{a}$ & $20,97 \mathrm{a}$ & $2,39 \mathrm{a}$ \\
\hline Vertical mulching a cada $10 \mathrm{~m}$ & $2,69 \mathrm{a}$ & $0,27 \mathrm{a}$ & $21,76 \mathrm{a}$ & $2,52 \mathrm{a}$ \\
\hline Vertical mulching a cada $5 \mathrm{~m}$ & 2,86 a & $0,31 \mathrm{a}$ & $19,98 \mathrm{a}$ & 3,35 a \\
\hline \multicolumn{5}{|c|}{ Intensidade de chuva $70 \mathrm{~mm} \mathrm{~h}^{-1}-$ (ciclo da cultura da soja) } \\
\hline Sem vertical mulching & $4,11 \mathrm{a}$ & $0,09 \mathrm{a}$ & $14,00 \mathrm{a}$ & $0,95 \mathrm{a}$ \\
\hline Vertical mulching a cada $10 \mathrm{~m}$ & $3,30 \mathrm{a}$ & $0,10 \mathrm{a}$ & $9,50 \mathrm{a}$ & $0,77 \mathrm{a}$ \\
\hline Vertical mulching a cada $5 \mathrm{~m}$ & $4,42 \mathrm{a}$ & $0,14 \mathrm{a}$ & $17,50 \mathrm{a}$ & $0,93 \mathrm{a}$ \\
\hline \multicolumn{5}{|c|}{ Intensidade de chuva $106 \mathrm{~mm} \mathrm{~h}^{-1}-$ (ciclo da cultura da soja } \\
\hline Sem vertical mulching & $3,63 \mathrm{a}$ & $0,22 \mathrm{a}$ & $11,50 \mathrm{a}$ & $0,53 \mathrm{a}$ \\
\hline Vertical mulching a cada $10 \mathrm{~m}$ & $3,08 \mathrm{a}$ & $0,26 \mathrm{a}$ & $8,50 \mathrm{a}$ & $0,88 \mathrm{a}$ \\
\hline Vertical mulching a cada $5 \mathrm{~m}^{(2)}$ & $\cdot$ & - & $\cdot$ & - \\
\hline
\end{tabular}

(1) Não houve diferença significativa entre as médias dos tratamentos pelo teste de Duncan a $5 \% .{ }^{(2)}$ As quantidades de nutrientes perdidas para este tratamento não foram obtidas devido a problemas nas amostras coletadas.

Para o autor, isso se deve ao maior teor do $\mathrm{K}$ no solo, também a sua maior solubilidade em água e maior mobilidade no solo, quando comparado ao P. O $\mathrm{N}$ total apresentou baixa concentração no escoamento superficial. Isso se deve ao fato de sua maior perda em semeadura direta ocorrer por lixiviação, reduzindo a concentração na enxurrada (Volk et al., 2004). De maneira geral, neste trabalho, as perdas de nutrientes e de $\mathrm{CO}$ obedeceram à seguinte ordem: $\mathrm{CO}>\mathrm{K}>$ $\mathrm{N}$ total $>\mathrm{P}$.

\section{Perda total de nutrientes e de carbono orgânico}

As perdas totais de nutrientes e de CO foram calculadas a partir dos volumes totais perdidos com diferentes intensidades de chuva simulada aplicada na cultura do trigo e da soja e das concentrações de nutrientes avaliados (Figuras 3, 4 e 5).

Somente houve diferença significativa durante o ciclo da cultura da soja, na qual o tratamento sem vertical mulching apresentou maiores perdas de $\mathrm{CO}$, $\mathrm{K}, \mathrm{N}$ total e $\mathrm{P}$ em relação aos tratamentos com vertical mulching. Entre os diferentes espaçamentos de vertical mulching, a diferença não foi significativa. Essa maior diferença entre a testemunha com os tratamentos de vertical mulching deve-se à maior perda total de água por escoamento superficial no tratamento sem vertical mulching. Quando as médias das concentrações de nutrientes e de CO em função dos tratamentos foram comparadas, não ocorreram diferenças significativas porque não foi considerado o volume total de água perdido, o que fez a diferença neste caso. Comportamento semelhante foi obsservado com as perdas totais: a maior foi de $\mathrm{CO}$, seguido do $\mathrm{K}$, do $\mathrm{N}$ total e, por último, o $\mathrm{P}$.

A semeadura direta causa menor impacto às águas superficiais que o sistema de preparo convencional e preparo mínimo, principalmente com os elementos $\mathrm{P}$ e K (Amaral et al., 2004). O vertical mulching junto

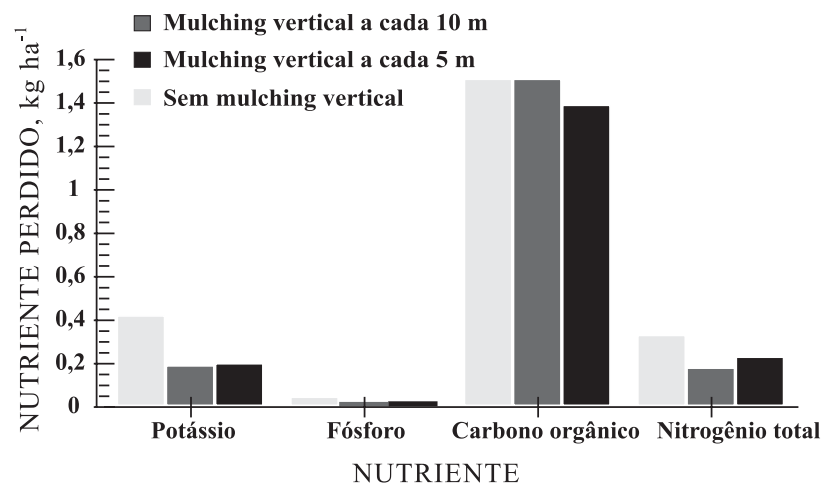

Figura 3. Perda de nutrientes e de carbono orgânico na água do escoamento superficial, obtida com chuva simulada com intensidade de $106 \mathrm{~mm} \mathrm{~h}^{-1}$, em Latossolo Vermelho distrófico típico durante o ciclo da cultura do trigo, em semeadura direta, nos tratamentos sem vertical mulching, vertical mulching a cada $10 \mathrm{~m}$ e vertical mulching a cada $5 \mathrm{~m}$. 


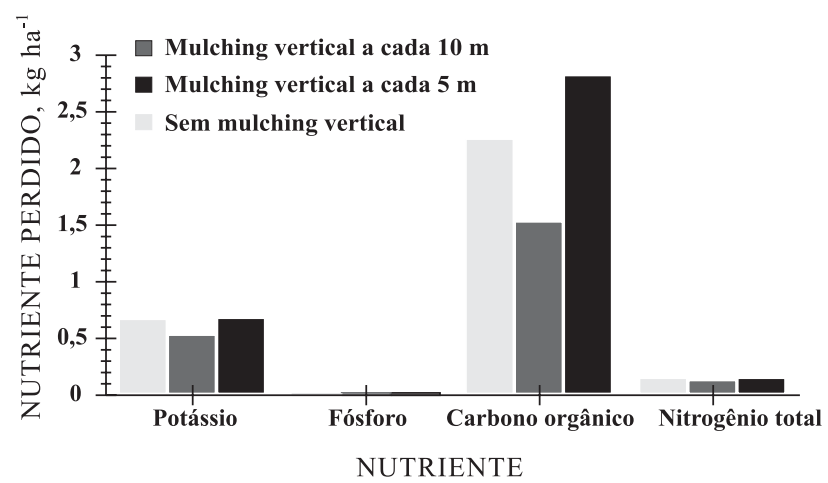

Figura 4. Perda de nutrientes e de carbono orgânico na água do escoamento superficial, obtida com chuva simulada com intensidade de $70 \mathrm{~mm} \mathrm{~h}^{-1}$, em Latossolo Vermelho distrófico típico, durante o ciclo da cultura da soja, em semeadura direta, nos tratamentos sem vertical mulching, vertical mulching a cada $10 \mathrm{~m}$ e vertical mulching a cada 5 m.

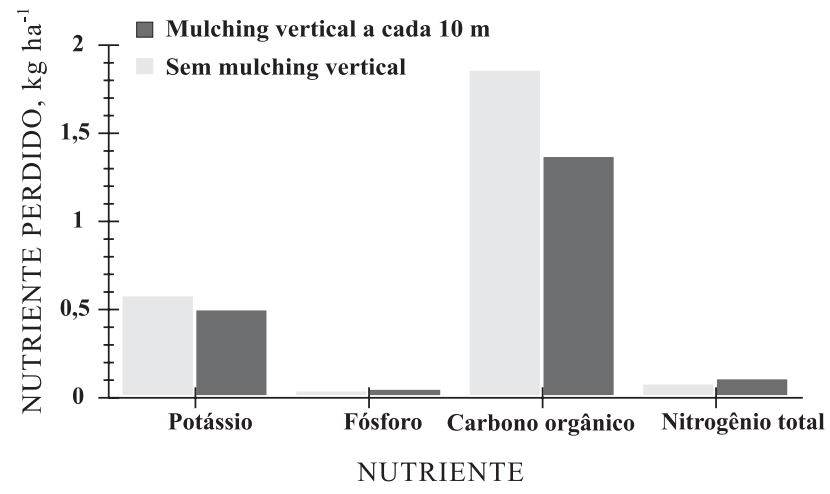

Figura 5. Perda de nutrientes e de carbono orgânico no escoamento superficial, obtida com chuva simulada com intensidade de $106 \mathrm{~mm} \mathrm{~h}^{-1}$, em Latossolo Vermelho distrófico típico, durante o ciclo da cultura da soja, em semeadura direta, nos tratamentos sem vertical mulching e vertical mulching a cada $10 \mathrm{~m}$.

à semeadura direta proporciona menor volume total de água escoado e diminui as perdas totais de nutrientes. Dessa forma, pode ser considerado como um grande aliado à conservação do meio ambiente na agricultura.

\section{CONCLUSÕES}

1. A utilização do vertical mulching em Latossolo Vermelho distrófico típico em semeadura direta reduz o escoamento superficial de água no solo em até 48,66 \%, com espaçamento de $10 \mathrm{~m}$ entre sulcos, e em até $54,54 \%$ com espaçamento de $5 \mathrm{~m}$, em relação ao mesmo sistema sem vertical mulching.
2. O vertical mulching em Latossolo Vermelho distrófico típico em semeadura direta aumenta a taxa de infiltração básica de água no solo em até 25,30\%, com espaçamento entre sulcos de $10 \mathrm{~m}$, e em até $29,07 \%$ com espaçamento de $5 \mathrm{~m}$, em relação ao mesmo sistema sem vertical mulching.

3. O vertical mulching em Latossolo Vermelho distrófico típico em semeadura direta, com espaçamento entre sulcos de $10 \mathrm{~m}$, pode controlar totalmente o escoamento superficial com intensidade de chuva de até $70 \mathrm{~mm} \mathrm{~h}^{-1}$, com duração de uma hora, quando o solo estiver com conteúdo de água menor ou igual a $37 \%$.

4. O vertical mulching não diminui a concentração dos elementos $\mathrm{K}, \mathrm{P}, \mathrm{CO}$ e $\mathrm{N}$ total no escoamento superficial. A sua eficiência manifestou-se na redução do volume do escoamento superficial, reduzindo significativamente as perdas totais de nutrientes e de carbono orgânico, em relação à testemunha sem vertical mulching.

\section{LITERATURA CITADA}

AMARAL, A.J.; BERTOL, I.; BARBOSA, F.T.; ENGEL, F.; BRIGNONI, L.F. \& RITTER, S.R. Efeito ambiental das perdas de nutrientes pela erosão hídrica. In: REUNIÃO BRASILEIRA DE MANEJO E CONSERVAÇÃO DO SOLO E DA ÁGUA, 15., Santa Maria, 2004. Manejo integrando a ciência do solo na produção de alimentos. Anais. Santa Maria, 2004. CD-ROM.

BRAKENSIEK, D.L.; OSBORN, H.B. \& RAWLS, W.J. Field manual for research in agricultural hydrology. Minneapolis, USDA, 1979. 547p.

BENAMI, A. \& OFEN, A. Irrigation engineering, sprinkler, trickle, surface irrigation, principles, design and agricultural practices. Haifa, IESP and International Irrigation Information Center, 1984. 257p.

BRIGNONI, L.F.; BERTOL, I. \& BARBOSA, F.T.; RITTER, S.R.; BRANBATTI, D.C.; ENGEL, F.L.; AMARAL, A.J. \& KAEFER, E.C. Perdas de $\mathrm{P}, \mathrm{K}$ e $\mathrm{CO}$ na água e no sedimento da erosão hídrica em sistemas de semeadura direta. In: REUNIÃO BRASILEIRA DE MANEJO E CONSERVAÇÃO DO SOLO E DA ÁGUA, 15., Santa Maria, 2004. Manejo integrando a ciência do solo na produção de alimentos. Anais. Santa Maria, 2004. CDROM.

COMPANHIA DE TECNOLOGIA DE SANEAMENTO AMBIENTAL - CETESB. Guia de coletas e preservação de amostras de água. São Paulo, 1989. 105p.

EMPRESA BRASIELIRA DE PESQUISA AGROPECUÁRIA EMBRAPA. Sistema brasileiro de classificação de solos. Brasília, Serviço de Produção de Informação, 1999. 412p.

HECKLER, J.C.\& SALTON, J.C. Palha: Fundamento do sistema plantio direto. Dourados, Embrapa Agropecuária Oeste, 2002. 26p. (Coleção Sistema Plantio Direto) 
HERBES, M.G. Escoamento superficial em sistema plantio direto com mulching vertical. Santa Maria, Universidade Federal de Santa Maria, 2003. 107p.

INSTITUTO DE PESQUISAS AGRONÔMICAS - IPAGRO Atlas agroclimático do Estado Rio Grande do Sul. Porto Alegre, 1989. 102p.

MONDARDO, A.; FARIAS, G.S.D.; CASTRO FILHO, C.D.; VIEIRA, M.J.; HENKLAIN, J.C. \& RUFINO, R.L. Metodologia e procedimento para avaliação de perdas por erosão em condições de chuva natural, no Paraná. In: ENCONTRO NACIONAL DE PESQUISA SOBRE CONSERVAÇÃO DO SOLO, 2., Passo Fundo, 1978. Anais. Passo Fundo, Embrapa-CNPT/SNLCS, 1978. p.67-71.

PRUSKI, F.F. A engenharia de conservação de solo e água aplicada à realidade brasileira. In: CONGRESSO BRASILEIRO DE ENGENHARIA AGRICOLA CONBEA, 33., Foz do Iguaçu, 2001. Anais. Foz do Iguaçu, 2001. CD-ROM.
RIGHES, A.A.; DENARDIN, J.E.; KOCHHANN, R.A.; NISHIJIMA, T. \& GARCIA, S.M. Vertical mulching e escoamento superficial no sistema plantio direto. In: CONGRESSO BRASILEIRO DE ENGENHARIA AGRÍCOLA, 31., Salvador, 2002. Anais. Salvador, 2002. CD-ROM.

TEDESCO, M.J.; GIANELLO, C.; BISSANI, C.A.; BOHNEN, H. \& VOLKWEISS, S.J. Análise de solos, plantas e outros materiais. 2.ed. Porto Alegre, Universidade Federal do Rio Grande do Sul, 1995. 174p. (Boletim Técnico, 5)

VEIGA, M.D. \& WILDNER, L.D.P. Manual para la instalación y conducción de experimentos de perdida de suelos. Santiago, EPAGRI/FAO, 1993. 34p.

VOLK, L.B.S.; COGO, N.P.; PORTZ, G. \& RECH, J.P.D. Perda de nutrientes por erosão hídrica em solo com e sem cultivo, na condição de semeadura direta. In: REUNIÃO BRASILEIRA DE MANEJO E CONSERVAÇÃO DO SOLO E DA ÁGUA, 15., Santa Maria, 2004. Manejo integrando a ciência do solo na produção de alimentos. Anais. Santa Maria, 2004. CD-ROM. 